\title{
Flavor stability assessment of lager beer: what we can learn by comparing established methods
}

\author{
Florian Lehnhardt ${ }^{1} \cdot$ Thomas Becker $^{1} \cdot$ Martina Gastl $^{1}$
}

Received: 22 November 2019 / Revised: 27 February 2020 / Accepted: 29 February 2020 / Published online: 16 March 2020

(c) The Author(s) 2020

\begin{abstract}
Beer is prone to flavor changes during aging that influence consumer acceptance within shelf life. The shelf life of beer is defined as the period over which flavor changes remain acceptable. Assessment of flavor changes caused by volatiles is typically achieved with a combination of sensory evaluation and gas chromatography-mass spectrometry (GC-MS). Volatile indicators causing flavor changes during beer aging are commonly determined with headspace solid-phase microextraction (HS-SPME), solvent-assisted flavor evaporation (SAFE), or steam distillation (SD). However, discrepancies occur when comparing results from different analytical methods that affect the assessment of the degree of flavor stability. This article discusses the effect of different established analytical methods on flavor stability assessment. Reaction potentials of de novo formation, release from adducts, and degradation are hypothesized to participate in the observed discrepancies, and evidence is verified using model systems. Three extraction methods were qualitatively compared by multiple gas chromatographyolfactometry experiments (GC-O) of a one-year, naturally aged, pale lager beer. SD showed the highest number of detected aroma compounds (41), followed by HS-SPME (33), and SAFE (26). Aroma intensities for SD were more pronounced for most aging indicators than with other methods. With SAFE, only 11 aging compounds could be identified confidently, with weak aroma intensities at GC-O, and this method was thereby excluded from further experiments. Certain aging compounds were calibrated for gas chromatography-mass spectrometry (GC-MS) from HS-SPME and SD, although most compounds were present at the lower limits of detection and quantification. Relative standard deviation and recoveries for all compounds were acceptable for both methods. Quantitative comparison was conducted for four different commercial pale lager beers at different stages of aging at $20^{\circ} \mathrm{C}$ (fresh, 5 months, 10 months). Aging-related changes of pale lager beer presented with altered profiles and behavior in SD compared to the non-invasive HS-SPME due to heat intake, and were borne out by GC-O results. Model systems were used to describe the impact of isolated aging-relevant mechanisms and precursors during distillation. Our findings suggest that results from different methods in reactive matrices should be compared cautiously, especially regarding aroma activity, and indicate that the most gentle or non-invasive method should be applied for analysis.
\end{abstract}

Keywords Beer aging $\cdot$ Flavor stability $\cdot$ Solid-phase microextraction $\cdot$ Steam distillation $\cdot$ Solvent-assisted flavor evaporation $\cdot$ Bound-state aldehydes

\section{Introduction}

Martina Gastl

Martina.Gastl@tum.de

Florian Lehnhardt

florian.lehnhardt@tum.de

1 Chair of Brewing and Beverage Technology, Technische Universität München, Weihenstephaner Steig 20, 85354 Freising, Germany
Sensory or flavor stability of lager beer is gaining importance due to growing consumer awareness in competitive and globalized beer markets [1]. During aging, desirable aroma compounds such as isoamyl acetate decrease [2] while undesirable aroma compounds increase in concentration. The main indicators thereof are aldehydes from Maillard reaction, Strecker degradation, and lipid oxidation. Other aroma compounds, such as hop degradation products, ketones, lactones, and ethyl esters also increase over time and contribute to an aged flavor [3]. The shelf life of beer 
is the length of time it can be stored before flavor changes render the product undesirable and is defined individually by each brewery for each product [4].

Saison et al. investigated the flavor units (FU) of a range of aging compounds in different lager beers. They found that acetaldehyde, (E)-2-nonenal, 3-methylbutanal, methional, diacetyl, furfuryl ethyl ether, and $\beta$-damascenone exhibited FUs of more than one in at least one of the three analyzed lager beers after forced aging $\left(3\right.$ weeks at $\left.40^{\circ} \mathrm{C}\right)$. Thus, these compounds were discussed to have direct impact on the sensory properties of these products. In the same study interactive effects of aging aldehydes were elucidated, highlighting the sensory impact of Strecker aldehydes. An exception to this was benzaldehyde, which showed FUs lower than 0.005 [5]. In another study, methional was the only compound to show odor activity values above 1 in a naturally aged lager beer [6].

The formation process of volatile aging compounds is highly complex, involving many physicochemical influences, such as temperature, time, $\mathrm{pH}$, and oxygen level, in packaged beer, in the malt, and in the brew house [3]. Furthermore, these mechanisms are interdependent and in equilibrium with non-volatiles throughout the brewing process $[7,8]$.

Assessment of flavor stability of lager beer is typically done by gas chromatography (GC) and sensory analysis. When assessing sensory stability by GC, different methods are used to determine volatile organic compounds (VOC), each with their own advantages and disadvantages. The ideal method would indiscriminately extract all key aroma compounds without modifying any of the VOCs.

Common techniques thereof used in laboratory practice for raw materials and beer are solvent extraction, distillation, headspace, and sorptive techniques, alone or in combination.

In solvent-assisted flavor evaporation (SAFE), solvent extracts (usually diethyl ether) are distilled under vacuum to separate volatile and non-volatile fractions. The volatiles are trapped using liquid nitrogen and further concentrated at low temperatures. Organic acids can be removed by washing with sodium carbonate and residual water by addition of sodium sulfate. Liquid foodstuffs can be distilled directly, whereas distillates can be extracted with solvents later [9]. This method is used to monitor volatiles during beer aging [10-12] and in flavor dilution assays.

In steam distillation (SD), samples are distilled at $100{ }^{\circ} \mathrm{C}$, and distillates are extracted using organic solvents alkaline $\mathrm{pH}$. Release of VOCs can be enhanced with the addition of sodium chloride. The extract is concentrated under a nitrogen stream and then analyzed via GC. This is also a reference method of MEBAK (Mitteleuropäische Brautechnische Analysenkommission) for the determination of aging compounds in wort and beer [13].

Headspace techniques (dynamic or purge and trap) extract the headspace above a given sample either statically or dynamically, possibly with enrichment on sorptive material. Studies have successfully applied such techniques for hops and aged beer [14, 15].

Solid-phase microextraction (SPME) and stir bar sorptive extraction (SBSE) are sorptive methods with adsorption enrichment of VOCs on a fiber and can be used to supplement headspace and liquid extractions. HS-SPME [16-20] and SBSE [21-23] are frequently used for volatiles in beer and wine, often with derivatization steps, such as $o$-(2,3,4,5,6-pentafluorobenzyl)hydroxylamine (PFBHA) for the enhanced determination of aldehydes.

Previous studies detail multiple comparisons of analytical methods, each specific to the given matrix and analyzed compounds. However, no study has yet compared established methods for assessing aging indicators in beer both qualitatively and quantitatively.

Richter et al. compared HSSE (headspace sorptive extraction), SBSE, HS-SPME, and SAFE on hop volatiles in beer and found that SAFE favors more alcohols and acids compared to the sorptive methods. When comparing extraction capacities, HSSE was better suited for esters and aldehydes, and SBSE for acids. HS-SPME extracted fewer compounds overall due to its limited surface area [24].

In another study, SBSE and SD were compared in detecting esters and organic acids in beer samples. Although the methods showed favorable correlation, SBSE was more sensitive to esters, while SD was more sensitive to higher alcohols, such as 2-phenylethanol [25]. The same authors also compared SBSE with SPME and found them to be similar in terms of linearity, recovery, and repeatability. In this study, HS-SPME proofed superior to SBSE due to shorter times of analysis [26].

Thompson-Witrick et al. compared HS-SPME and SAFE for aroma-active compounds using $\mathrm{GC}-\mathrm{O}$ in lambic beer. SAFE extracted more organic acids, while HS-SPME isolated more esters due to their higher volatility [27].

Thus, it can be concluded that the applied extraction technique influences the obtained results both qualitatively and quantitatively (each method having its advantages and disadvantages). In a complex sample such as beer, where precursors for de novo synthesis as well as bound-state aroma compounds are present, it is also likely that temperature, $\mathrm{pH}$ shifts, and solvent extraction affect the extracted VOC profile. Accordingly, this study evaluated the influence of the extraction method in beer aging quantification via aromaactive compounds using $\mathrm{GC}-\mathrm{O}$ to assess the profile of compounds extracted by each method. Extraction methods were then compared quantitatively over the course of aging and to gain insight into their differences using model distillation systems. 


\section{Materials and methods}

\section{Chemicals}

The chemicals, $o$-(2,3,4,5,6-pentafluorobenzyl)hydroxylamine hydrochloride ( $\geq 99 \%$ ), ethyl 2-methyl propanoate (99\%), ethyl 2-methyl butanoate (99\%), ethyl 4-methyl pentanoate ( $\geq 97 \%), \beta$-damascenone $(\geq 98 \%), \gamma$-nonalactone (98\%), 2-aminoacetophenone (98\%), ethyl 2-phenylacetate (99\%), ethyl nicotinate (99\%), 2-methylpropanal ( $\geq 99.5 \%)$, 2-methylbutanal (95\%), 3-methylbutanal (97\%), 2-phenylacetaldehyde ( $\geq 90 \%)$, methional ( $\geq 97 \%$ ), benzaldehyde ( $\geq 99.5 \%)$, pentanal $(\geq 97.5 \%)$, hexanal (98\%), heptanal (95\%), (E)-2-nonenal (97\%), acetaldehyde ( $\geq 99.5 \%)$, isovaleric acid (99\%), D- $(+)$-xylose $(\geq 99 \%)$, L-arginine ( $\geq 98 \%$ ), L-lysine ( $\geq 98 \%$ ), L-leucine ( $\geq 98 \%)$, 2-(furan-2-yl)1,3-thiazolidine-4-carboxylic acid ( $\geq 98 \%$ ), and methylglyoxal $\left(\sim 40 \%\right.$ in $\left.\mathrm{H}_{2} \mathrm{O}\right)$ were obtained from Sigma-Aldrich (St. Louis, MO, USA). Ethyl 3-methyl butanoate ( $\geq 99.7 \%$, Fluka Analytical), dimethyl trisulfide ( $\geq 98 \%$, SAFC), furfuryl ethyl ether (95\%, Fluorochem), 2-furfural ( $\geq 99.0 \%$, Fluka Analytical), ammonia (25\%, VWR International S.A.S., Leuven, Belgium), dichloromethane (for HPLC, VWR International S.A.S., Leuven, Belgium), sodium chloride (VWR International S.A.S., Leuven, Belgium), DCHA-Iso ICS-I4 (65.2\% w/w; Labor Veritas, Zurich, Switzerland), and diethyl ether (for analysis, Merck, Darmstadt, Germany) were obtained from the indicated manufacturers. 2-(isobutyl)-1,3-thiazolidine-4-carboxylic acid was synthesized as previously described and confirmed by ${ }^{1} \mathrm{H}-\mathrm{NMR}$ [28].

\section{Qualitative and quantitative method comparison}

\section{Internal standards}

An internal standard mixture $\left(\sim 1 \mathrm{mg} \mathrm{L}^{-1}\right.$ of ethyl 2-methyl pentanoate, methyl undecanoate, and $p$-fluorobenzaldehyde in ethanol) was used for quantification. Ethyl 2-methyl pentanoate was used for quantification of highly volatile, underivatized compounds; methyl undecanoate for moderately volatile, underivatized compounds; and $p$-fluorobenzaldehyde was used for all aldehydes (derivatized compounds). Figure 4 indicates which internal standard was used for the respective compounds. Standards were prepared anew for every measurement.

\section{HS-SPME procedure}

Five $\mathrm{mL}$ of cooled, unfiltered sample were placed in a $20-\mathrm{mL}$ headspace vial and incubated at $40{ }^{\circ} \mathrm{C}$ together with $50 \mu \mathrm{L}$ of internal standard. HS-SPME extraction was performed as described by Saison et al. [19] using a CAR-PDMS-DVB fiber. The fiber was injected splitless at $270{ }^{\circ} \mathrm{C}$ into the GC.

\section{SD procedure}

Steam distillation was performed according to MEBAK 2.23.4. Briefly, $2 \mathrm{~mL}$ of internal standard mixture together with $5 \mathrm{~mL}$ ethanol p. a. were spiked into $200 \mathrm{~mL}$ of cooled sample. Using a Büchi K-355 distillation apparatus (BÜCHI Labortechnik AG, Flawil, Switzerland), the sample was distilled for $4.5 \mathrm{~min}$, and $100 \mathrm{~mL}$ of distillate were collected. Twenty $\mathrm{mL}$ of distillate were then removed. Subsequently, $20.8 \mathrm{~g}$ of sodium chloride, $4 \mathrm{~mL}$ of ammonia (25\%) and $1 \mathrm{~mL}$ of dichloromethane were added to the sample. The sample was shaken for $30 \mathrm{~min}$ and then centrifuged at $0{ }^{\circ} \mathrm{C}$ and $2400 \mathrm{rpm}$ for $15 \mathrm{~min}$. The organic phase was transferred to a vial, concentrated under nitrogen, and $2 \mu \mathrm{L}$ were injected at a $1 / 5$ split at $250^{\circ} \mathrm{C}$ into the GC.

\section{SAFE procedure}

The SAFE extraction was performed according to previous reports [9]. Briefly, $200 \mathrm{~mL}$ of beer sample, $2 \mathrm{~mL}$ of internal standard mixture, and $2 \mathrm{~g}$ of sodium chloride were poured into the SAFE apparatus (Glasbläserei Bahr, Manching, Germany). The distillation was performed at $40{ }^{\circ} \mathrm{C}$ and under vacuum at $<9 \times 10^{-6} \mathrm{mbar}$, and the distillate was trapped in a flask cooled with liquid nitrogen. The distillate was then extracted with diethyl ether $(3 \times 100 \mathrm{~mL})$, organic acids were removed by washing with saturated sodium carbonate solution $(2 \times 20 \mathrm{~mL})$, and the sample was dried with $\mathrm{NaSO}_{4}$. The extract was concentrated to $1 \mathrm{~mL}$ in a Vigreux column at $42{ }^{\circ} \mathrm{C}$, and $2 \mu \mathrm{L}$ were injected at a $1 / 5$ split at $250{ }^{\circ} \mathrm{C}$ into the GC.

\section{GC-MS parameters}

The GC (GC-Ultra 1300, Thermo Scientific Inc., Waltham, MA, USA) was equipped with a DB-5 column (length, $60 \mathrm{~m}$; inner diameter, $0.25 \mathrm{~mm}$; film thickness, $0.25 \mu \mathrm{m}$; Thermo Scientific Inc., Waltham, MA, USA) and two split/splitless injectors. Helium was used as the carrier gas (flow rate $1.85 \mathrm{~mL} / \mathrm{min}$ ). The initial temperature was maintained at $60{ }^{\circ} \mathrm{C}$ for $4 \mathrm{~min}$, followed by heating at $5 \mathrm{~K} / \mathrm{min}$ up to a final temperature of $250^{\circ} \mathrm{C}$, which was held for $3 \mathrm{~min}$.

The GC was coupled to a single quad mass spectrometer (ISQ QD, Thermo Scientific Inc., Waltham, MA, USA) via a transfer line that was heated to $250{ }^{\circ} \mathrm{C}$. Ionization was achieved in EI mode. A full scan mode (m/z 35-350) with a dwell time of $0.02 \mathrm{~s}$ was applied for the analysis. Each sample was analyzed in triplicate. Peak detection was performed in Xcalibur 3.1.66.10 (Thermo Scientific Inc., Waltham, 
MA, USA), and identification was performed via the addition of pure compounds and the NIST database.

\section{GC-0}

The naturally aged sample (pale lager beer, aged for one year at $20^{\circ} \mathrm{C}$ ) was extracted by SAFE, SD, and HS-SPME as described above. Olfactometry assessment was performed by two panelists in multiple repetitions $(n=5-7)$, trained specifically on aging aromas using different sniffing samples. The olfactometry system used in this study was an ODP 3 (Gerstel GmbH \& Co. KG, Mülheim an der Ruhr, Germany). It was equipped with a temperature controller heated to $250{ }^{\circ} \mathrm{C}(\mathrm{C} 200$, Gerstel GmbH \& Co. KG, Mülheim an der Ruhr, Germany). The makeup gas was synthetic air that was humidified $(10 \mathrm{~mL} / \mathrm{min}$. The gas stream was splitted equally using a y-splitter after the GC column, one part going to the MS, the other via a transfer line (heated to $250{ }^{\circ} \mathrm{C}$ ) to the olfactory port. The lengths of the capillaries were adjusted to compensate any pressure differences between MS and olfactory port (at atmospheric pressure). Time, quality, and intensity of odors ( $1=$ weak; $2=$ medium; $3=$ high intensity $)$ were recorded manually by another person. The means of the odor intensities that were perceived reproducibly (more than once in 5-7 experiments) are displayed in Figs. 1-3 and summarized in Table 1.

\section{Calibration and validation}

Standard addition was used for calibration of SD and HSSPME to minimize matrix effects and changes during sample preparation. Standard solutions (target compounds in ethanol) were added to fresh pale lager at ten different dilutions and measured as technical duplicates. For each compound, a calibration range was determined with a linearity $>0.99$. Relative standard deviation (RSD) was assessed in a five-fold replicate analysis of a 1-year-aged $\left(20^{\circ} \mathrm{C}\right)$ pale lager beer sample. Recoveries were prepared by adding a medium calibration concentration to a beer sample in duplicate, and accepted if the values were between 80 and $110 \%$. Limit of detection (LOD) and limit of quantification (LOQ) were determined as previously described using the standard deviation of the y-intercept ( $\sigma$; peak area of analytes divided by peak area of internal standard) and the slope (s) of the calibration curve (LOD $=3.3 \sigma / s ; \mathrm{LOQ}=10 \sigma / s)$ [29]. The LOD and LOQ determined by visual examination were far lower than the indicated values in Fig. 4 as red and black lines respectively.

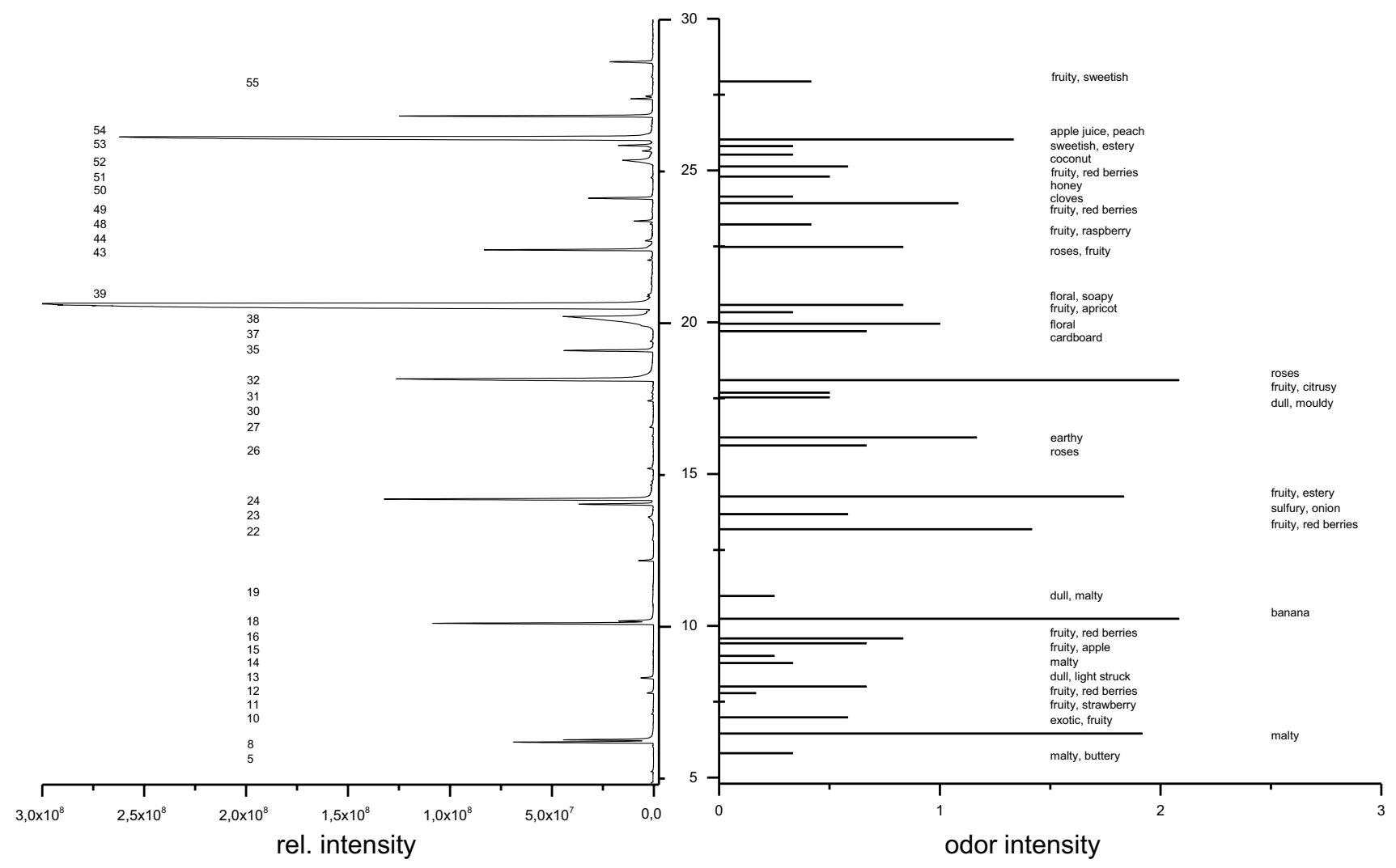

Fig. 1 Aromagram after SPME extraction. Left, GC-MS chromatogram with detected compounds (numbers correspond with compounds in Table 1); right, odor descriptions and intensities for detected compounds $(n=6)$ 


\section{Beer samples}

All beer samples were purchased in the freshest condition possible. The pale lager beer investigated with $\mathrm{GC}-\mathrm{O}$ was aged for 12 months at $20{ }^{\circ} \mathrm{C}$ prior to analysis. It had 4.82 vol.\% alcohol, a color of $6.8 \mathrm{EBC}$, a $\mathrm{pH}$ of 4.57 , and 20 IBUs. For quantitative comparison, four commercially available beer samples (pale lager beers) were purchased and aged naturally at $20{ }^{\circ} \mathrm{C}$. All samples were brewed in accordance with German purity laws. Samples were analyzed fresh, at 5 months, and at 10 months.

\section{Breakdown, formation, and release reactions in model systems}

Model distillations were carried out in phosphate buffer at $\mathrm{pH} 4.5$ according to the MEBAK method [13]. Blank runs were used to identify fragments from the sample workup. Possible breakdown reactions were investigated by a methional system $(0.02 \mathrm{mM})$. Possible formation reactions were investigated for ethyl 3-methylbutanoate $(40 \mathrm{mM}$ isovaleric acid; $0.01 \mathrm{mM}$ DCHA), furfural (1.3 mM xylose; $1.3 \mathrm{mM}$ xylose and $0.4 \mathrm{mM}$ arginine/lysine; $0.1 \mathrm{mM}$ FURFCys), and 3-methylbutanal (2 $\mathrm{mM}$ leucine and $3 \mathrm{mM}$ methyl glyoxal; $0.02 \mathrm{mM} 3-\mathrm{MB}-\mathrm{Cys}$ ). Semi-quantitative yield rates were achieved by 1 -point calibration in duplicate of the corresponding target compound.

\section{Data analysis}

Except as otherwise stated, all samples were analyzed in triplicate and means and standard deviations were calculated. Vapor pressures were obtained from www.pubchem.ncbi. nlm.nih.gov. Two-way ANOVAs were performed to uncover statistical differences within sample sets. Tukey-Kramer's test was used to further divide statistical groups.

\section{Results and discussion}

\section{Qualitative comparison using GC-0}

Aromagrams for the three extraction techniques (Figs. 1-3) covered in this study are presented individually and then compared with one another subsequently. On the left of each aromagram the GC chromatograms and on the right the aroma descriptors of the detected compounds and aroma intensities of $\mathrm{GC}-\mathrm{O}$ are indicated. This makes it possible to quickly match the detected aroma compounds with their odor impression. The numbers of the assigned compounds on the left in the aromagrams match those for the compounds in Table 1, wherein all compounds can be compared directly among methods.
HS-SPME

HS-SPME uncovered 33 volatile aroma compounds in the aged sample, 26 of which could be identified by retention index, odor impression, and mass spectrum. Most were typical beer aroma compounds such as 3-methyl butanol, 3-methylbutyl acetate, linalool, and 2-phenylethanol. Thirteen aging related aroma compounds were also detected; seven esters, two aldehydes, and dimethyl trisulfide, 2-aminoacetophenone, $\gamma$-nonalactone, and $\beta$-damascenone. Figure 1 shows an aromagram of the HS-SPME analysis $(n=6)$.

\section{SD}

SD uncovered 41 volatile compounds of which 31 were identified, four were tentatively identified, and six remained unknown. Nineteen of the detected aroma compounds are known as aging compounds and comprised four aldehydes, nine esters, 2,4,5-trimethyl-1,3-dioxolane, diethoxyethane, dimethyl trisulfide, 2 -aminoacetophenone, $\gamma$-nonalactone, and $\beta$-damascenone. Figure 2 shows the aromagram of the $\mathrm{SD}$ analysis $(n=5)$.

\section{SAFE}

The SAFE procedure yielded 26 detected aroma compounds in $\mathrm{GC}-\mathrm{O}$, but only 11 could be identified by retention index, odor impression, and mass spectrum. Thirteen aging compounds were detected and comprised six esters, three aldehydes, and diethoxyethane, dimethyl trisulfide, 2-aminoacetophenone, and $\beta$-damascenone. Figure 3 shows the aromagram of the SAFE analysis $(n=7)$.

\section{Summary of GC-O}

GC-O allows the coupling of gas chromatographic separation and sensory evaluation for a comprehensive analysis of possible aroma-active compounds. In this study, three common extraction methods were compared, with different underlying physicochemical principles. Data comparison was considered valid because peak areas were generally comparable. For the detected compounds, qualitative, and semi-quantitative differences in odor intensity were observed among the methods. HS-SPME results most resembled the actual composition of the headspace above the sample at $40{ }^{\circ} \mathrm{C}$ without solvents and were thereby comparable to human orthonasal olfaction. SD (high temperature intake) and SAFE (low temperature intake) reflect volatiles extracted by dichloromethane (DCM) and diethyl ether (DEE), respectively. As such, the most important factor for HS-SPME is volatility, whereas that for SD and SAFE is solubility in the applied solvent. In addition, extraction enrichment occurs during HS-SPME. For 


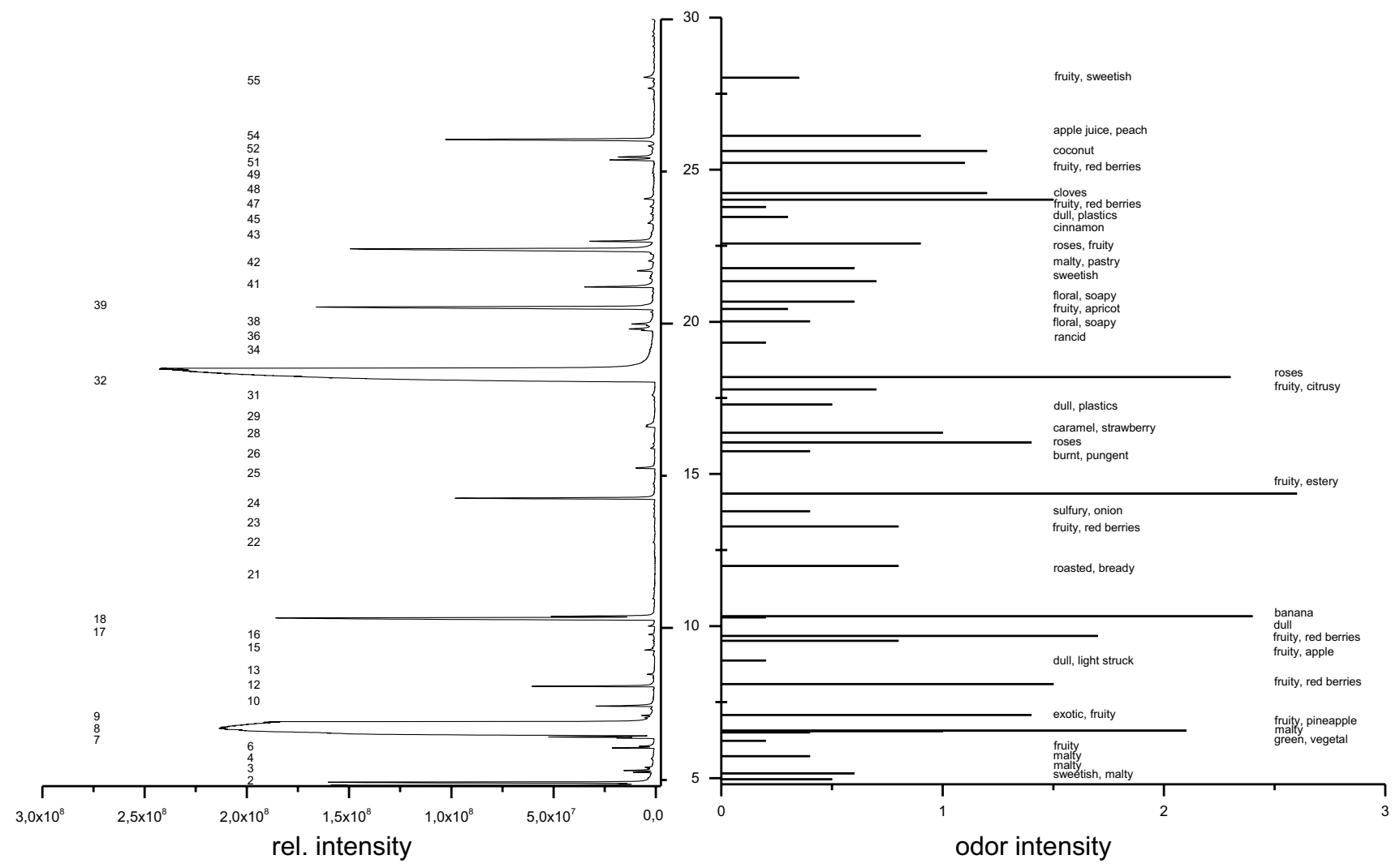

Fig. 2 Aromagram after SD extraction. Left, GC-MS chromatogram with detected compounds (numbers correspond with compounds in Table 1); right, odor descriptions and intensities for detected compounds $(n=5)$

SD and SAFE, no selective enrichment occurs resulting in significant concentration differences among volatiles. This can lead to saturation of certain compounds (see peak shapes of 3-methylbutanol or 2-phenylethanol in Figs. 2, 3) and limitations in concentration of the liquid extract. Different methods can be applied and the results combined to overcome discrepancies among methods and the resulting under- or overestimation of specific aroma contributions [30]. Highly and moderately volatile compounds were favored in HS-SPME, although in a complex matrix, such as beer, some of these compounds might be formed, degraded, or discriminated.

In this study, 3-methylbutanol $\left(0.4 \mathrm{kPa}\right.$ at $\left.20{ }^{\circ} \mathrm{C}\right)$ was detected at the highest intensity by HS-SPME. In contrast, the less polar and more volatile 3-methylbutanal (3-MB; $6.1 \mathrm{kPa}$ at $20^{\circ} \mathrm{C}$ ) was not detected by HS-SPME, but was detected by SD. These results suggest that $3-\mathrm{MB}$ is formed during thermal distillation at $100^{\circ} \mathrm{C}$, as gentle distillation under vacuum at $40{ }^{\circ} \mathrm{C}$ did not result in perceivable amounts of 3-MB.

The two acetals 2,4,5-trimethyl-1,3-dioxolane (acetaldehyde $+2,3$-butanediol) and diethoxyethane (acetaldehyde +2 molecules of ethanol) also apparently formed during distillation at higher temperatures, as these compounds were only detected at low concentrations by HS-SPME and SAFE

Given the fact that ethyl 3-methylbutanoate (3MB2) and ethyl 2-methylpropanoate (2MP2) show higher threshold in literature compared to ethyl 2-methylbutanoate (2MB2) and both former ones were detected more intensely in $\mathrm{GC}-\mathrm{O}$ it was concluded that $3 \mathrm{MB} 2$ and $2 \mathrm{MP} 2$ were present in higher concentrations than 2MB2 [31]. This is most likely due to the higher amounts of humulone precursors in finished beer. Degradation thereof appeared to be temperature-dependent.

$\gamma$-nonalactone showed the highest odor intensity in SD, which also indicates its formation from precursors during distillation. The same observation was made for acetylfuran, and was tentatively made for benzothiazole in SD.

Conversely, methional was only detected in SAFE, indicating too little sensitivity in HS-SPME for this compound and its degradation at higher temperatures. It was not detected by HS-SPME. (E)-2-nonenal (T2N) was apparently degraded during distillation. 


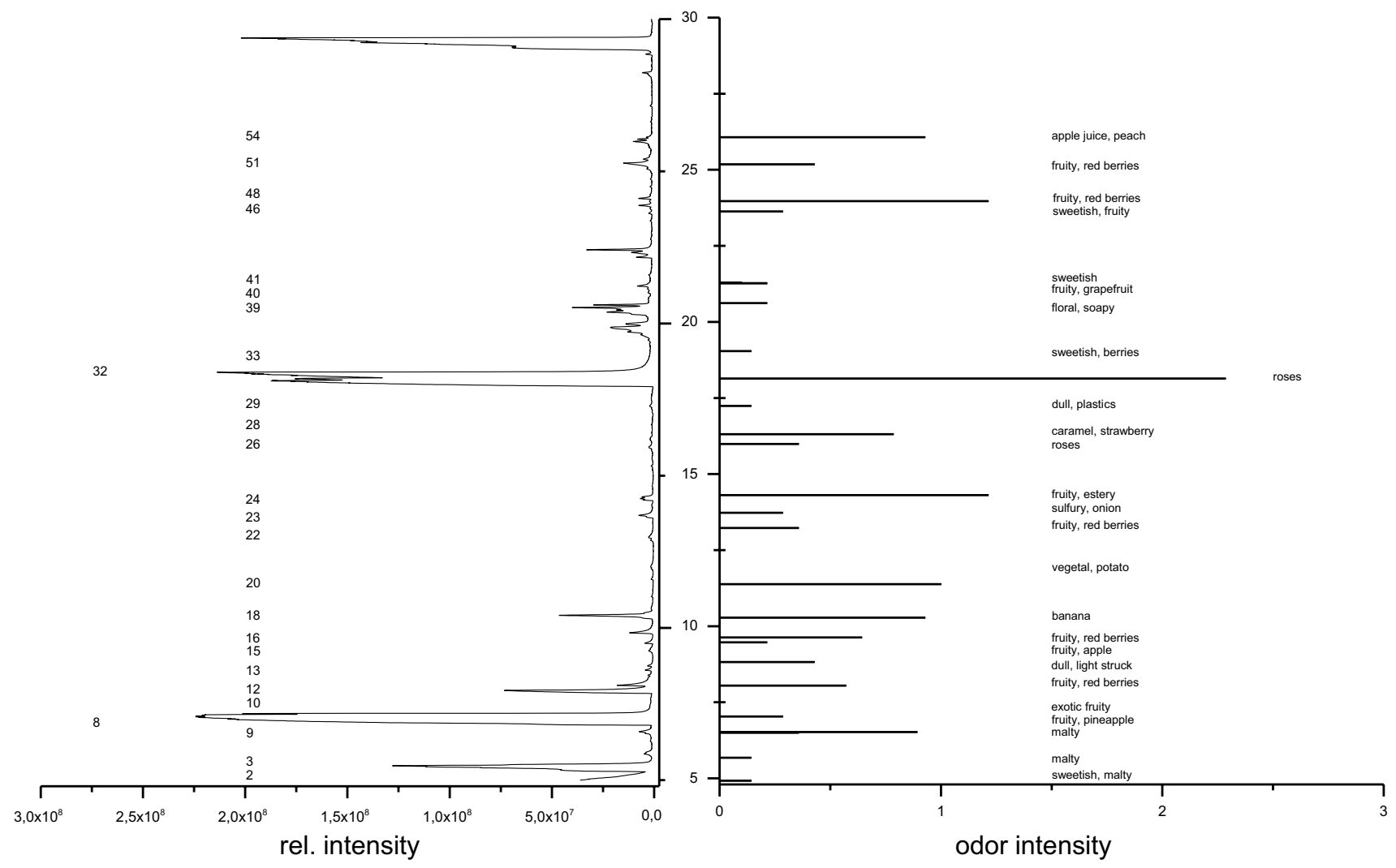

Fig. 3 Aromagram after SAFE extraction. Left, GC-MS chromatogram with detected compounds (numbers correspond with compounds in Table 1); right, odor descriptions and intensities for detected compounds $(n=7)$

\section{Quantitative comparison}

Due to low odor intensity and difficulties in identifying aroma compounds, SAFE was further excluded from quantitative comparisons even though it has been used in the quantification of aging compounds in beer in previous work; of note, one such study utilized GC-MS [10].

Below quantitative comparisons of HS-SPME and SD of four different samples, after calibration and validation of each method are displayed.

\section{Calibration and validation}

SPME and SD were compared using a 10-point matrixassisted calibration curve $\left(\mathrm{y}=\mathrm{area}_{\text {analyte }} / \mathrm{area}_{\text {internal standard }}\right.$; $x=$ concentration $\left._{\text {analyte }}\left[\mu \mathrm{g} \mathrm{L}^{-1}\right]\right)$ prepared for chosen compounds relevant to beer aging [6]. Three internal standards were applied: ethyl 2-methylpentanoate (A), methyl undecanoate (B), and p-fluorobenzaldehyde (C). To further characterize the methods, correlation coefficient of calibration curve $\left(\mathrm{R}^{2}\right), \mathrm{LOD}, \mathrm{LOQ}, \mathrm{RSD}$ and recovery rate were assessed.
Figure 4 shows the calibrated ranges for HS-SPME and SD for each compound. LOD (red) and LOQ (black) are represented by vertical lines.

One-way ANOVA showed the means of the lowest points of the calibration curve were not significantly different at $\alpha=0.05$ (HS-SPME, $0.84 \mu \mathrm{g} \mathrm{L}^{-1}$; SD, $4.11 \mu \mathrm{g}$ $\left.\mathrm{L}^{-1} ; p=0.094\right)$; the same was found for the highest points of the calibration curve (HS-SPME, $42.3 \mu \mathrm{g} \mathrm{L}{ }^{-1}$; SD, $40.0 \mu \mathrm{g} \mathrm{L}^{-1} ; p=0.875$ ), the mean of $\mathrm{R}^{2}$ (HS-SPME, 0.995; $\mathrm{SD}, 0.994 ; p=0.721$ ), and the mean of RSD (HS-SPME, $6.9 \%$; SD, $6.1 \% ; p=0.16)$. SD tended to yield lower RSD values, likely due to the higher volumes of sample and internal standard and therefore minimized sampling error compared to HS-SPME.

The means of LOD and LOQ also showed no statistical differences (mean LOD HS-SPME, $1.22 \mu \mathrm{g} \mathrm{L}^{-1}$; mean LOD $\mathrm{SD}, 2.65 \mu \mathrm{g} \mathrm{L}^{-1} ; p=0.12$ ). For most compounds, however, HS-SPME yielded lower LODs and LOQs, with the exception of the less volatile ethyl cinnamate, benzaldehyde, and phenylacetaldehyde, among others. This was especially pronounced for highly volatile compounds such as $2 \mathrm{MB} 2$ or 2-methylbutanal. Nonetheless, recoveries were acceptable for all calibrated compounds. 
Table 1 Compound number, retention index, odor impression, and odor intensity (mean of all experiments); identification by retention index, odor impression, and mass spectrum (compared to NIST database)

\begin{tabular}{|c|c|c|c|c|c|c|}
\hline \multirow{2}{*}{$\begin{array}{l}\text { Com- } \\
\text { pound } \\
\text { number }\end{array}$} & \multirow[t]{2}{*}{ Retention index } & \multirow[t]{2}{*}{ Compound } & \multirow[t]{2}{*}{ Odor impression } & \multicolumn{3}{|l|}{ Odor intensity } \\
\hline & & & & $\operatorname{SPME}(n=6)$ & $\mathrm{SD}(n=5)$ & SAFE $(n=7)$ \\
\hline 1 & 553 & Diacetyl & Buttery & & 0.6 & \\
\hline 2 & 634 & 2-Methylpropanol & Sweetish, malty & & 0.5 & 0.1 \\
\hline 3 & 667 & 3-Methylbutanal & Malty & & 0.6 & \\
\hline 4 & 678 & 2-Methylbutanal & Malty & & 0.4 & 0.1 \\
\hline 5 & 703 & 2,3-Pentadione & Malty, buttery & 0.3 & & \\
\hline 6 & 718 & Ethyl propanoate & Fruity & & $0.2^{\mathrm{a}}$ & \\
\hline 7 & 730 & 2,4,5-Trimethyl-1,3-dioxolane & Green, vegetal & & 0.4 & \\
\hline 8 & 732 & 3-Methylbutanol & Malty & 1.9 & 1 & 0.4 \\
\hline 9 & 733 & Diethoxyethane & Fruity, pineapple & & 2.1 & 0.9 \\
\hline 10 & 756 & ethyl 2-Methylpropanoate & Exotic fruity & 0.6 & 1.4 & $0.3^{\mathrm{a}}$ \\
\hline 11 & 792 & n. i & Fruity, strawberry & 0.2 & & \\
\hline 12 & 802 & Ethyl butanoate & Fruity, red berries & 0.7 & 1.5 & 0.6 \\
\hline 13 & 827 & 3-Methylbut-2-en-1-thiol & Dull, light struck & 0.3 & $0.2^{\mathrm{a}}$ & $0.4^{\mathrm{a}}$ \\
\hline 14 & 835 & n. i & Malty & 0.3 & & \\
\hline 15 & 849 & Ethyl 2-methylbutanoate & Fruity, apple & 0.7 & 0.8 & $0.2^{\mathrm{a}}$ \\
\hline 16 & 854 & Ethyl 3-methylbutanoate & Fruity, red berries & 0.8 & 1.7 & $0.6^{\mathrm{a}}$ \\
\hline 17 & 874 & n. i & Dull & & 0.2 & \\
\hline 18 & 876 & 3-Methylbutyl acetate & Banana & 2.1 & 2.4 & 0.9 \\
\hline 19 & 901 & n. i & Dull, malty & 0.3 & & \\
\hline 20 & 911 & Methional & Vegetal, potato & & & $1.0^{\mathrm{a}}$ \\
\hline 21 & 928 & 2-Acetylfuran & Roasted, bready & & 0.8 & \\
\hline 22 & 967 & ethyl 4-Methylpentanoate & Fruity, red berries & 1.4 & 0.8 & $0.4^{\mathrm{a}}$ \\
\hline 23 & 982 & Dimethyl trisulfide & Sulfury, onion & 0.6 & 0.4 & $0.3^{\mathrm{a}}$ \\
\hline 24 & 999 & Ethyl hexanoate & Fruity, estery & 1.8 & 2.6 & 1.2 \\
\hline 25 & 1039 & n. i & Burned, pungent & & 0.4 & \\
\hline 26 & 1054 & Phenylacetaldehyde & Roses & 0.7 & 1.4 & 0.4 \\
\hline 27 & 1058 & n. i & Earthy & 1.2 & & \\
\hline 28 & 1059 & $\begin{array}{l}\text { 4-Hydroxy-2,5-dimethyl-3-Fura- } \\
\text { none }\end{array}$ & Caramel, strawberry & & $1^{\mathrm{a}}$ & $0.8^{\mathrm{a}}$ \\
\hline 29 & 1088 & n. i & Dull, plastics & & 0.5 & 0.1 \\
\hline 30 & 1098 & n. i & Dull, moldy & 0.5 & & \\
\hline 31 & 1103 & Linalool & Fruity, citrusy & 0.5 & 0.7 & \\
\hline 32 & 1116 & 2-Phenylethanol & Roses & 2.1 & 2.3 & 2.3 \\
\hline 33 & 1146 & n. i & Sweetish, berries & & & 0.1 \\
\hline 34 & 1154 & n. i & Rancid & & 0.2 & \\
\hline 35 & 1170 & (E)-2-Nonenal & Cardboard & 0.7 & & \\
\hline 36 & 1174 & n. i & Floral, soapy & & 0.4 & \\
\hline 37 & 1178 & n. i & Floral & 1.0 & & \\
\hline 38 & 1191 & Diethyl succinate & Fruity, apricot & 0.3 & 0.3 & \\
\hline 39 & 1199 & Ethyl octanoate & Floral, soapy & 0.8 & 0.6 & 0.2 \\
\hline 40 & 1220 & n. i & Fruity, grapefruit & & & 0.2 \\
\hline 41 & 1222 & Ethyl nicotinate & Sweetish & & 0.7 & $0.1^{\mathrm{a}}$ \\
\hline 42 & 1238 & Benzothiazole & Malty, pastry & & $0.6^{\mathrm{a}}$ & \\
\hline 43 & 1266 & 2-Phenylethyl acetate & Roses, fruity & 0.8 & 0.9 & \\
\hline 44 & 1292 & n. i & Fruity, raspberry & 0.4 & & \\
\hline 45 & 1297 & Cinnamaldehyde & Cinnamon & & 0.3 & \\
\hline
\end{tabular}


Table 1 (continued)

\begin{tabular}{|c|c|c|c|c|c|c|}
\hline \multirow{2}{*}{$\begin{array}{l}\text { Com- } \\
\text { pound } \\
\text { number }\end{array}$} & \multirow[t]{2}{*}{ Retention index } & \multirow[t]{2}{*}{ Compound } & \multirow[t]{2}{*}{ Odor impression } & \multicolumn{3}{|l|}{ Odor intensity } \\
\hline & & & & $\operatorname{SPME}(n=6)$ & $\operatorname{SD}(n=5)$ & $\operatorname{SAFE}(n=7)$ \\
\hline 46 & 1305 & n. i & Sweetish, fruity & & & 0.3 \\
\hline 47 & 1309 & n. i & Dull, plastics & & 0.2 & \\
\hline 48 & 1318 & 2-Aminoacetophenone & Fruity, red berries & 1.1 & 1.5 & $1.2^{\mathrm{a}}$ \\
\hline 49 & 1326 & 2-Methoxy-4-vinylphenol & Cloves & 0.3 & 1.2 & \\
\hline 50 & 1350 & n. i & Honey & 0.5 & & \\
\hline 51 & 1362 & Ethyl 3-phenylpropionate & Fruity, red berries & 0.6 & 1.1 & $0.4^{\mathrm{a}}$ \\
\hline 52 & 1377 & $\gamma$-Nonalactone & Coconut & 0.3 & 1.2 & \\
\hline 53 & 1386 & Ethyl (Z)-4-decenoate & Sweetish, estery & 0.3 & & \\
\hline 54 & 1397 & $\beta$-Damascenone & Apple juice, peach & 1.3 & 0.9 & 0.9 \\
\hline \multirow[t]{6}{*}{55} & 1471 & Ethyl cinnamate & Fruity, sweetish & 0.4 & 0.4 & \\
\hline & \multicolumn{2}{|c|}{ Sum of detected aroma compounds } & & 33 & 41 & 26 \\
\hline & \multicolumn{2}{|c|}{ Sum of detected aging compounds } & & 13 & 19 & 13 \\
\hline & \multicolumn{2}{|c|}{ Sum of identified aroma compounds } & & 26 & 31 & 11 \\
\hline & \multicolumn{2}{|c|}{ Sum of tentatively identified aroma compoundsa } & & 0 & 4 & 11 \\
\hline & \multicolumn{2}{|c|}{ Sum of non-identified aroma compounds } & & 7 & 6 & 4 \\
\hline
\end{tabular}

${ }^{a}$ Tentatively identified by retention index and odor impression

Aging compounds are printed in bold

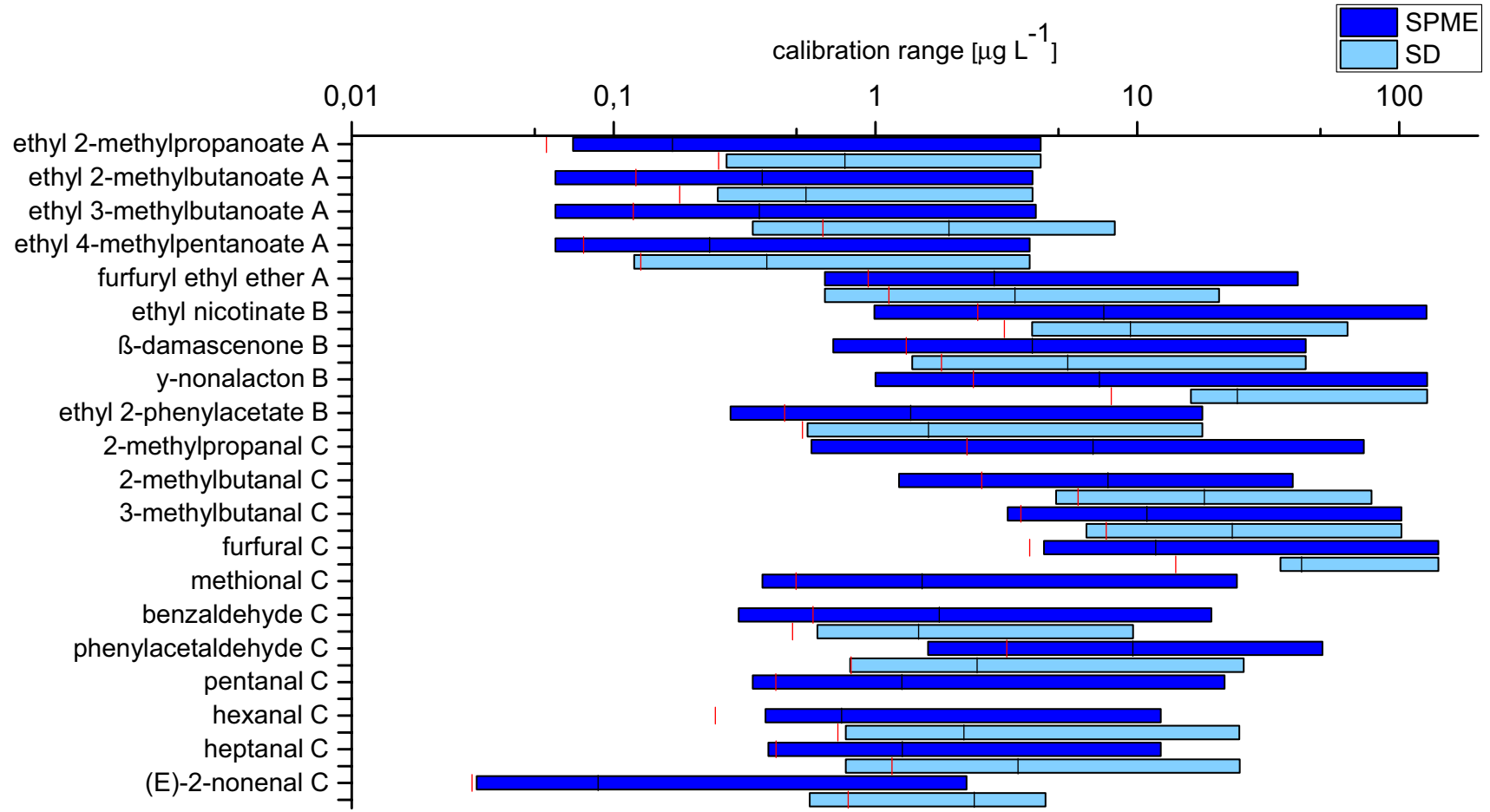

Fig. 4 Calibration ranges. LOD, red marks; LOQ, black marks of volatile aging indicators for SPME and SD. Letters after compound names indicate the standard used for calibration, as follows: A, ethyl-2-methylpentanoate; B, methyl undecanoate; C, p-fluorobenzaldehyde 

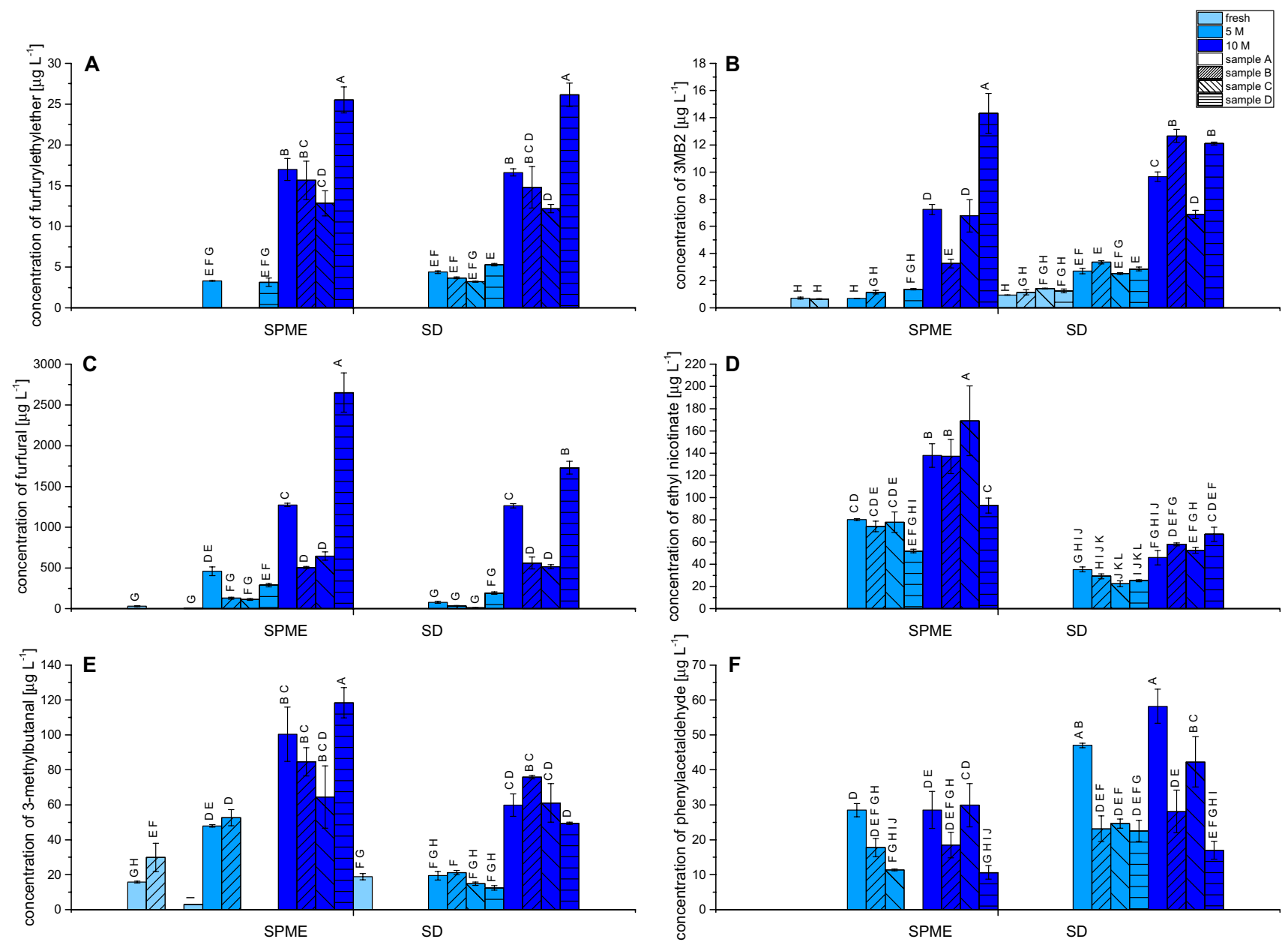

Fig. 5 Selected compound concentrations of fresh, 5 months and 10 months-aged beer from samples a, b, c, and d. a furfuryl ethyl ether, $p=0.65$; b 3MB2, $p=0.15$; $\mathbf{c}$ furfural, $p=0.86$; $\mathbf{d}$ ethyl nicotinate, $p=0.002$; e 3-MB, $p=0.08$; f phenylacetaldehyde, $p=0.07$.

Numbers in brackets show $p$ values resulting from ANOVA; letters above bars represent statistical groups as designated by Tukey-Kramer's test

\section{Quantification of aging indicators}

The quantification of volatile aging indicators with HSSPME and SD was performed on four different samples at fresh and aged conditions (5 and 10 months at $20^{\circ} \mathrm{C}$ ). Methional, pentanal, and 2-methylpropanal were not quantified in SD due to inadequate calibration. Figure 5 shows values for selected compounds over the course of aging. ANOVA at $\alpha=0.05$ revealed statistical differences between the methods, especially for T2N $(p=0.0012)$, ethyl nicotinate $(p=0.0015)$, and others. The letters above the bars indicate statistical groups resulting from the Tukey-Kramer test.

Only a few compounds appear above their respective LOQ for either method; despite this, most compounds presented with acceptable peaks on the GC-MS. Due to the method used for calculating LOD and LOQ, higher values

resulted in comparisons to visual assessment or signal-tonoise ratio [29].

Furfuryl ethyl ether was found to behave similarly for both methods. It was not quantifiable by HS-SPME in samples $\mathrm{B}$ and $\mathrm{C}$ at 5 months despite a slightly lower LOQ. 3MB2 also appeared to behave similarly between both methods, although a considerable deviation between them was observed in sample B. Furfural and furfuryl ethyl ether behaved linearly over all samples $\left(R^{2}=0.83\right)$. The concentrations of furfural were well-matched at 10 months for all but sample D. Again, a high amount of precursors that will be partly converted to the resp. analytes is suspected to underlie this result.

3-MB only was comparable after 10 months in samples $\mathrm{B}$ and $\mathrm{C}$, and fresh in sample $\mathrm{A}$.

In most compounds, HS-SPME yielded higher concentrations than SD. One explanation might be matrix 
influence during calibration, especially in SD. Through the heat intake, fragmentation, de novo formation, and release from adducts may occur and alter the ratios of dosed calibration solution to endogenous volatiles in the sample. One exception to this trend was phenylacetaldehyde, which was present in higher concentrations in samples $\mathrm{A}, \mathrm{C}$, and $\mathrm{D}$ in SD. In sample B, only a small increase during aging was observed and the obtained concentrations fit well between the two methods. The underlying reasons for this behavior should be investigated further, with special focus on the compound's non-volatile precursors such as imines, cysteine-, or bisulfite-adducts.

The choice of method and analyzed aging indicators remains crucial for the assessment of flavor stability. While for most indicators in HS-SPME sample D appeared highest in concentration, only the assessment of 3-MB and phenylacetaldehyde with SD resulted in the lowest observed concentrations. These results underscore the importance of analyzing a broad range of indicators to cover a diversity of reactions and influences.

This quantitative comparison strongly indicated that the extraction technique influences the obtained results to a greater or lesser degree depending on the aging indicator and matrix or sample. Few indicators were found to behave comparably; many differed significantly. The considerable discrepancies between the methods in this study were ascribed to the large amount of precursors affected during sample workup.

\section{Breakdown, formation, and release reactions in model systems}

Model systems were applied to further delineate the observed qualitative and quantitative results and to clarify the influence of sample matrix and thermal intake on detected VOCs. These systems enabled an investigation into possible mechanisms of breakdown, de novo formation, and release of adducts. Sample preparation by SD is accompanied by several invasive steps. First, ethanol is added and the sample is distilled at $100{ }^{\circ} \mathrm{C}$. Then, ammonia, sodium chloride, and dichloromethane are added to the distillate. The model system used in this case was phosphate buffer $(\mathrm{pH}$ 4.5 ) with spiked different precursors representing de novo formation and release reaction from bound-state compounds.

In a blank run of distillation without spiked compounds, multiple chlorinated and non-chlorinated fragments could be identified such as: 1,2-dichloroethene, ethyl acetate, chloroform, 2-methylbutan-2-ol, 3-methylbutan-2-one, 2-chloro-2-methylbutane, diethoxyethane, and others. This might be an underlying cause of the observed higher LODs and LOQs in SD.

\section{Breakdown of methional during distillation}

To explore why methional was not detected in SD using GC-O and not possible to calibrate in SD at relevant concentrations, methional was added to the model system and distilled. It was possible to identify dimethyl disulfide, dimethyl trisulfide, methional diethyl acetal, a methional dimer, and a methional trimer in considerable amounts in addition to methional in the model system (Fig. 6). This partly explains the behavior observed in the former experiments.

\section{Formation mechanisms of 3MB2 during distillation}

Figure 7 a shows possible precursors for $3 \mathrm{MB} 2$. Esterification of isovaleric acid with ethanol was observed. Its impact

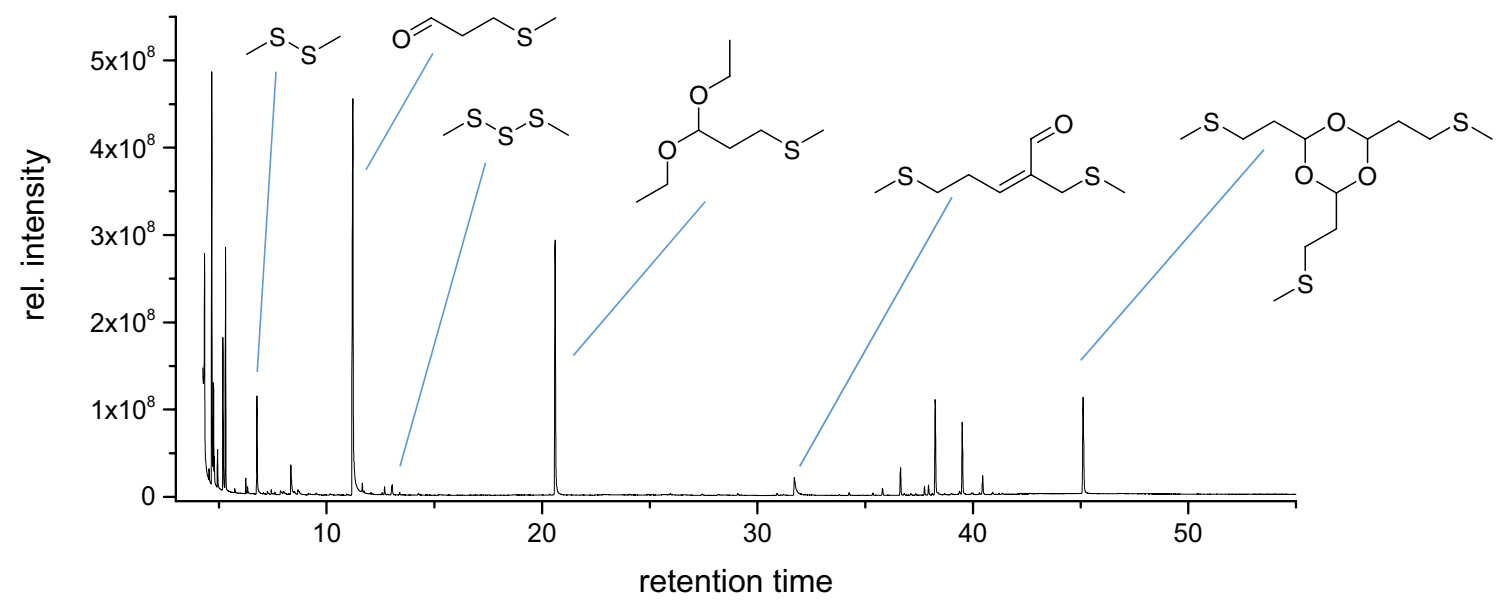

Fig. 6 Fragments of methional in model solution after distillation. Dimethyl disulfide, methional, dimethyl trisulfide, methional diethyl acetal, a methional dimer, and a methional trimer are represented 
A

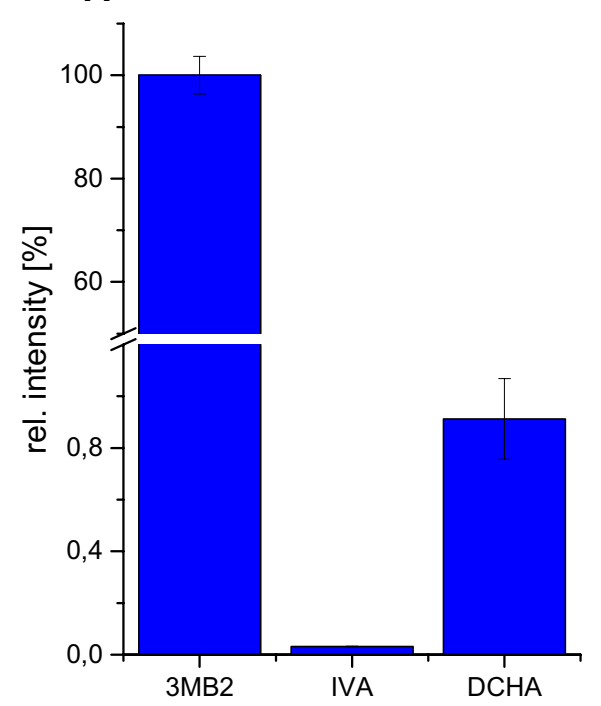

B

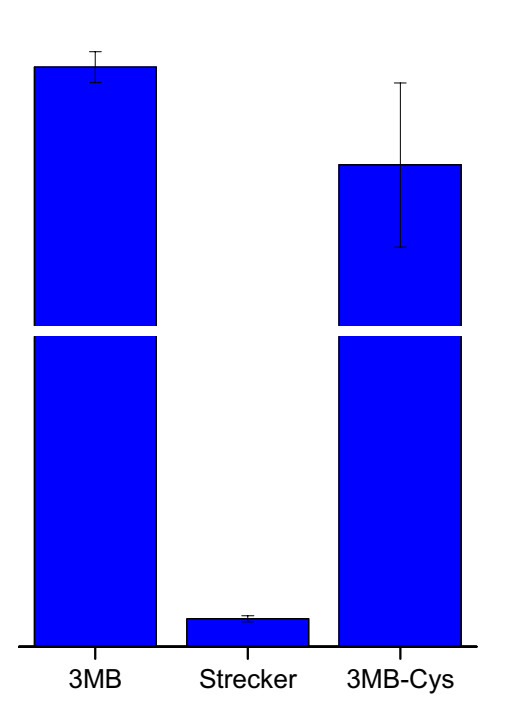

C

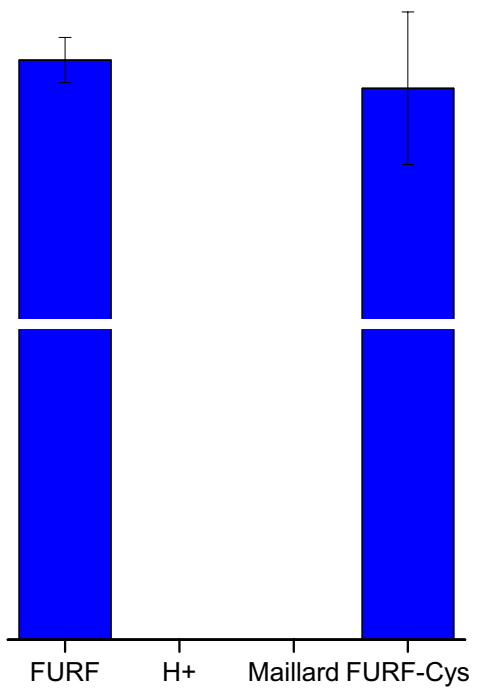

Fig. 7 Possible formation pathways after distillation for 3MB2 (isovaleric acid, DCHA), 3-MB (Strecker reaction bound-state adduct 3-MBCys), and FURF (acidic hydrolysis, Maillard reaction bound-state adduct FURF-Cys)

on the analysis, however, seems negligible due to the small amounts of precursors (isovaleric acid) normally present in beer matrices or reaction conditions were not sufficient during distillation. Conversely, isohumulones (in the form of DCHA) were promising precursors of 3MB2 during distillation. A GC-O experiment on DCHA distillate revealed fruity odors for $2 \mathrm{MB} 2$ and $3 \mathrm{MB} 2$, indicating high aroma activity (data not shown).

\section{Formation mechanisms of 3-MB during distillation}

Possible precursors for 3-MB are shown in Fig. 7b. Strecker reaction occurred to a minor extent. Anyhow, due to the high amount of leucine in beer matrices the impact of this pathway has a high impact and yields significant amounts of aldehydes during distillation. The compound 2-(isobutyl)-1,3-thiazolidine-4-carboxylic acid (3-MB-Cys), a promising representative bound-state aldehyde, was almost fully converted to aldehyde form during distillation. So if samples contain this compound or other bound-state forms in reasonable amounts, the analysis will be strongly influenced by this pathway.

\section{Formation mechanisms of furfural during distillation}

The formation of furfural was not observed via acidic hydrolysis nor Maillard reaction probably due to the distillation time (Fig. 7c). Presumably, distillation time was too short with only $4.5 \mathrm{~min}$ and therefore, reaction conditions were not sufficient. It was once again observed that 2-(furan-2-yl)-1,3-thiazolidine-4-carboxylic acid (FURFCys) was almost fully converted to the aldehyde form during distillation, resulting in the same consequences as those discussed for 3-MB-Cys.

\section{Conclusion}

This study used GC-O to evaluate qualitative differences between HS-SPME, SD, and SAFE in the detection of VOCs that occurred due to the underlying physicochemical properties (volatility and polarity) of each method. SD detected the most VOCs while SAFE was insensitive to most aging-related compounds. Some discrepancies could be mitigated by tedious solvent fractionation of extracts or more complex instrumental setups such as GCxGC couplings. SPME prevented solvent discrimination, yet fiber discrimination remains possible. Differences in detected compounds might also be explained by harsh distillation conditions (thermal intake), especially for reactive food matrices. Observed and potential breakdown and formation mechanisms were discussed.

Further, quantitative differences were discovered between HS-SPME and SD. Few aging indicators matched well, most showed significant discrepancies in calibration and quantification behavior. Differences among samples were also observed, with one sample in particular differing more severely between the methods than others. These results suggest that in addition to invasive steps during distillation, matrix composition might also be a crucial factor, and special consideration must be given to sensory conclusions. 
Observed differences were further delineated using model distillations. The detected chlorinated and non-chlorinated fragments in blank runs might have caused LODs and LOQs to be higher in SD. Fragmentation of methional during distillation did not allow its calibration at adequate concentrations. In this study, bound-state precursors (representably cysteinylated aldehydes) were found to be the most important aldehyde precursors during distillation. Strecker reaction also occurred to a considerable extent; Maillard reaction did not.

Our data indicate that for complex matrices such as beer, an agreement about method and calibration procedures is necessary for comparability between studies. Preferably, the most non-invasive method should be chosen. Furthermore, to assess sensory stability in the most holistic way non-volatile precursors should always play an important role.

Acknowledgements Open Access funding provided by Projekt DEAL. This IGF Project (AiF $20151 \mathrm{~N}$ ) is supported via AiF within the programme for promoting the Industrial Collective Research (IGF) of the German Ministry of Economic Affairs and Energy (BMWi), based on a resolution of the German Parliament.

\section{Compliance with ethical standards}

Conflict of interest The authors declare that they have no conflict of interest.

Compliance with ethics requirements All procedures performed in studies involving human participants were in accordance with the ethical standards of the institutional and national research committee and with the 1964 Helsinki declaration and its later amendments or comparable ethical standards.

Open Access This article is licensed under a Creative Commons Attribution 4.0 International License, which permits use, sharing, adaptation, distribution and reproduction in any medium or format, as long as you give appropriate credit to the original author(s) and the source, provide a link to the Creative Commons licence, and indicate if changes were made. The images or other third party material in this article are included in the article's Creative Commons licence, unless indicated otherwise in a credit line to the material. If material is not included in the article's Creative Commons licence and your intended use is not permitted by statutory regulation or exceeds the permitted use, you will need to obtain permission directly from the copyright holder. To view a copy of this licence, visit http://creativecommons.org/licenses/by/4.0/.

\section{References}

1. Jaskula-Goiris B, de Causmaecker B, de Rouck G, Aerts G, Paternoster A, Brae J et al (2019) Influence of transport and storage conditions on beer quality and flavour stability. J Inst Brew 125(1):60-68

2. Vanderhaegen B, Neven H, Coghe S, Verstrepen KJ, Verachtert H, Derdelinckx G (2003) Evolution of chemical and sensory properties during aging of top-fermented beer. J Agric Food Chem 51(23):6782-6790
3. Lehnhardt F, Gastl M, Becker T (2018) Forced into aging: analytical prediction of the flavor-stability of lager beer. Crit Rev Food Sci Nutr Rev 59:1-35

4. Bamforth CW (2011) 125th Anniversary review: the non-biological instability of beer. J Inst Brew 117(4):488-497

5. Saison D, de Schutter DP, UyttenhoveDelvaux BF, Delvaux FR (2009) Contribution of staling compounds to the aged flavour of lager beer by studying their flavour thresholds. Food Chem 114(4):1206-1215

6. Lehnhardt F, Steiner J, Gastl M, Becker T (2018) Prediction power and accuracy of forced ageing - matching sensory and analytical results for lager beer. Brew Sci 71:39-48

7. Ditrych M, Filipowska W, de Rouck G, Jaskula-Goiris B, Aerts G, Andersen ML et al (2019) Investigating the evolution of free staling aldehydes throughout the wort production process. Brew Sci 72:10-17

8. Bustillo Trueba P, Jaskula-Goiris B, de Clippeleer J, Goiris K, Praet T, Sharma UK et al (2019) Validation of an ultra-high performance liquid chromatography-mass spectrometry method for the quantification of cysteinylated aldehydes and application to malt and beer samples. J Chromatogr A 1064:460-467

9. Engel W, Bahr W, Schieberle P (1999) Solvent assisted flavour evaporation-a new and versatile technique for the careful and direct isolation of aroma compounds from complex food matrices. Eur Food Res Technol 209(3-4):237-241

10. Wietstock PC, Kunz T, Methner F-J (2016) The relevance of oxygen for the formation of Strecker aldehydes during beer production and storage. J Agric Food Chem 64:8035-8044

11. Wietstock PC, Kunz T, Methner F-J (2016) Influence of hopping technology on oxidative stability and staling-related carbonyls in pale lager beer. Brew Sci 69:73-84

12. Fritsch HT, Schieberle P (2005) Identification based on quantitative measurements and aroma recombination of the character impact odorants in a Bavarian Pilsner-type beer. J Agric Food Chem 53(19):7544-7551

13. Jacob F (ed) (2012) MEBAK Brautechnische Analysemethoden - Würze, Bier Methodensammlung der Mitteleuropäischen Brautechnischen Analysenkommission, Selbstverlag der MEBAK. Freising-Weihenstephan, Biermischgetränke

14. Eichhorn P (1991) Untersuchungen zur Geschmacksstabilität des Bieres. Dissertation, TU München

15. Aberl A, Coelhan M (2012) Determination of volatile compounds in different hop varieties by headspace-trap GC/MS - in comparison with conventional hop essential oil analysis. J Agric Food Chem 60:2785-2792

16. Andrés-Iglesias C, Nešpor J, Karabín M, Montero O, Blanco CA, Dostálek P (2016) Comparison of carbonyl profiles from Czech and Spanish lagers: traditional and modern technology. LWT Food Sci Technol 66:390-397

17. Baert JJ, de Clippeleer J, Jaskula-Goiris B, van Opstaele F, de Rouck G, Aerts G et al (2015) Further elucidation of beer flavor instability: the potential role of cysteine-bound aldehydes. J Am Soc Brew Chem 73:243-252

18. Canuti V, Conversano M, Calzi ML, Heymann H, Matthews MA, Ebeler SE (2009) Headspace solid-phase microextraction-gas chromatography-mass spectrometry for profiling free volatile compounds in Cabernet Sauvignon grapes and wines. J Chromatogr A 1216(15):3012-3022

19. Saison D, de Schutter DP, Delvaux F, Delvaux FR (2008) Optimisation of a complete method for the analysis of volatiles involved in the flavour stability of beer by solid-phase microextraction in combination with gas chromatography and mass spectrometry. J Chromatogr A 1190(1-2):342-349

20. Vesely P, Lusk L, Basarova G, Seabrooks J, Ryder D (2003) Analysis of aldehydes in beer using solid-phase microextraction 
with on-fiber derivatization and gas chromatography/mass spectrometry. J Agric Food Chem 51(24):6941-6944

21. Castro LF, Ross CF (2015) Determination of flavour compounds in beer using stir-bar sorptive extraction and solid-phase microextraction. J Inst Brew 121(2):197-203

22. Tsuji H, Mizuno A (2010) Volatile compounds and the changes in their concentration levels during storage in beers containing varying malt concentrations. J Food Sci 75(1):C79-84

23. Ochiai N, Sasamoto K, Daishima S, Heiden A, Hoffmann A (2003) Determination of stale-flavor carbonyl compounds in beer by stir bar sorptive extraction with in-situ derivatization and thermal desorption-gas chromatography-mass spectrometry. J Chromatogr A 1:101-110

24. Richter TM, Eyres GT, Silcock P, Bremer PJ (2017) Comparison of four extraction methods for analysis of volatile hop-derived aroma compounds in beer. J Sep Sci 40(22):4366-4376

25. Horák T, Čulík J, Kellner V, Čejka P, Hašková D, Jurková M et al (2011) Determination of selected beer flavours: comparison of a stir bar sorptive extraction and a steam distillation procedure. $\mathrm{J}$ Inst Brew 117(4):617-621

26. Horák T, Čulík J, Kellner V, Jurková M, Čejka P, Hašková D et al (2010) Analysis of selected esters in beer: comparison of solid phase microextraction and stir bar sorptive extraction. J Inst Brew 116(1):81-85

27. Thompson-Witrick KA, Rouseff RL, Cadawallader KR, Duncan SE, Eigel WN, Tanko JM et al (2015) Comparison of two extraction techniques, solid-phase microextraction versus continuous liquid-liquid extraction/solvent-assisted flavor evaporation, for the analysis of flavor compounds in gueuze lambic beer. J Food Sci 80(3):C571-C576

28. Bustillo Trueba P, de Clippeleer J, van der Eycken E, Guevara Romero JS, de Rouck G, Aerts G et al (2018) Influence of pH on the stability of 2-substituted 1,3-thiazolidine-4-carboxylic acids in model solutions. J Am Soc Brew Chem 76(4):272-280

29. Shrivastava A, Gupta V (2011) Methods for the determination of limit of detection and limit of quantitation of the analytical methods. Chronicles Young Sci 2(1):21

30. Brattoli M, Cisternino E, Dambruoso PR, de Gennaro G, Giungato P, Mazzone A et al (2013) Gas chromatography analysis with olfactometric detection (GC-O) as a useful methodology for chemical characterization of odorous compounds. Sensors 13:16759-16800

31. Kishimoto T, Wanikawa A, Kono K, Shibata K (2006) Comparison of the odor-active compounds in unhopped beer and beers hopped with different hop varieties. J Agric Food Chem 54(23):8855-8861

Publisher's Note Springer Nature remains neutral with regard to jurisdictional claims in published maps and institutional affiliations. 